\title{
Moderating effects of age on relationships between attitudes to aging and well-being outcomes
}

DOI:

10.1080/13607863.2019.1619167

\section{Document Version}

Accepted author manuscript

Link to publication record in Manchester Research Explorer

\section{Citation for published version (APA):}

Mohd Faudzi, F. N. B., Armitage, C. J., Bryant, C., \& Brown, L. J. E. (Accepted/In press). Moderating effects of age on relationships between attitudes to aging and well-being outcomes. Aging and Mental Health.

https://doi.org/10.1080/13607863.2019.1619167

\section{Published in:}

Aging and Mental Health

\section{Citing this paper}

Please note that where the full-text provided on Manchester Research Explorer is the Author Accepted Manuscript or Proof version this may differ from the final Published version. If citing, it is advised that you check and use the publisher's definitive version.

\section{General rights}

Copyright and moral rights for the publications made accessible in the Research Explorer are retained by the authors and/or other copyright owners and it is a condition of accessing publications that users recognise and abide by the legal requirements associated with these rights.

\section{Takedown policy}

If you believe that this document breaches copyright please refer to the University of Manchester's Takedown Procedures [http://man.ac.uk/04Y6Bo] or contact uml.scholarlycommunications@manchester.ac.uk providing relevant details, so we can investigate your claim.

\section{OPEN ACCESS}




\section{Moderating effects of age on relationships between attitudes to aging and well-being} outcomes

This is a pre-copyedited, author-produced PDF of an article accepted for publication in Aging and Mental Health following peer review. The final published version of the article Faudzi et al (2019) will be available from the publisher's website https://www.tandfonline.com/loi/camh20 :

Farah Nadia M.Faudzi ${ }^{1,2}$, Christopher J. Armitage ${ }^{1,3,4}$, Christina Bryant ${ }^{5}$, Laura J.E. Brown* ${ }^{1}$

${ }^{1}$ Manchester Centre for Health Psychology, Division of Psychology and Mental Health, University of Manchester, Manchester Academic Health Science Centre, UK

${ }^{2}$ School of Applied Psychology, Social Work and Policy, College of Arts and Sciences, Northern University of Malaysia, Malaysia

${ }^{3}$ NIHR Manchester Biomedical Research Centre, Manchester University NHS Foundation Trust, Manchester Academic Health Science Centre, UK

${ }^{4}$ NIHR Greater Manchester Patient Safety Translational Research Centre

${ }^{5}$ Melbourne School of Psychological Sciences, University of Melbourne, Melbourne, Australia

*Address correspondence to Dr Laura Brown, Division of Psychology and Mental Health, and Manchester Centre for Health Psychology, The University of Manchester, Zochonis Building, Brunswick Street, Manchester, M13 9PL, United Kingdom.

E-mail: laura.brown@.manchester.ac.uk 


\begin{abstract}
Objectives: More positive attitudes to aging are associated with better health and wellbeing outcomes. This study examined whether chronological age moderated relationships between attitudes to aging and wellbeing outcomes, and whether these relationships differ according to the specific attitudinal construct measured.
\end{abstract}

Method: Participants were 911 adults aged 18-60 years (mean $=36.63$ years). Attitudes to ageing were measured using the Malay Reactions to Ageing Questionnaire (M-RAQ), which focuses on respondents' anticipated reactions to being aged over 65 years, and the Malay Anxiety about Ageing Scale (M-AAS), which additionally captures respondents' fears and anxieties about current aging and older people. Wellbeing outcomes were measured using the Warwick- Edinburgh Mental Well-being Scale (WEMWBS) and the Satisfaction with Life Scale (SWLS).

Results: More positive attitudes to ageing were associated with higher levels of wellbeing and life satisfaction after controlling for age, gender, education, and self-rated health. Age moderated the relationships between the M-AAS and wellbeing and life satisfaction, with stronger relationships in younger adults. No moderating effects of age were found for the M-RAQ.

Conclusion: The difference in the moderating effects of age between measures suggests that the two attitudinal constructs captured by these two measures operate in different ways. In particular, the current emotional/anxiety components of attitudes to ageing may differentially affect wellbeing at different ages. This suggests that interventions aimed at the promotion of wellbeing through coping with aging-related anxieties might be particularly well-suited to younger adults, who may be less able to respond effectively to the anxieties they experience. 
Keywords: attitudes to ageing, age-stereotypes, mental health, wellbeing, satisfaction with life. 


\section{Introduction}

There is now considerable evidence that older adults' attitudes to aging are associated with health and well-being outcomes (Bryant, Bei, Gilson, Komiti, Jackson \& Judd, 2012; Shenkin, Laidlaw, Allerhand, Mead, Starr \& Deary, 2014, Kalfoss, Low \& Molzahn 2010). There is also emerging evidence that similar patterns are found in younger adults (Wurm, Diehl, Kornadt, Westerhof \& Wahl, 2017). For instance, Thorpe, Pearson, Schluter, Spittlehouse and Joyce (2014) reported correlations between attitudes to ageing and chronic physical and mental health in participants aged 49-51, whilst Joshi, Malhotra, Lim, Ostbye and Wong, (2010) reported correlations between attitudes to ageing and wellbeing outcomes in participants aged over 42. Longitudinal studies have also shown that positive attitudes to ageing among middle aged adults (40-64 years) predicted an increase in sporting activity six years later (Wurm, Tomasik \& Tesch-Romer, 2010). Similarly, more positive attitudes to ageing at baseline predicted healthier eating patterns over a one-year follow-up period in older (65+ years), middleaged (36-64 years) and younger (18-35 years) adults, even after controlling for participants' gender, eating behavior, health, and body mass index (Klusmann, Sproesser, Wolff \& Renner, 2017), suggesting that the effects of attitudes to ageing occur throughout the adult lifespan.

There are two key questions that can be asked about relationships between attitudes to aging and health and well-being outcomes in younger adults. First, although these relationships have been observed in a range of different age groups, the extent to which age moderates these relationships is not yet known. This is important because a better understanding of the moderating effect of age on these relationships would help with intervention development by identifying the points in the life cycle at which people's attitudes to aging are most closely associated with relevant health and wellbeing outcomes. 
Theoretical accounts of the development and operation of internalized views about ageing support the suggestion that the effects of attitudes on health and wellbeing are likely to differ by age. For instance, stereotype embodiment theory proposes that, whilst stereotypes about aging and older people are internalized early in life, the effects of these stereotypes will differ with age as they become increasingly more self-relevant (Levy, 2009). This is supported by data from Klusmann et al. (2017), who showed that, whilst the direct effects of attitudes to ageing on eating patterns were similar across older, middle-aged and younger age groups, the extent to which these relationships were mediated by self-efficacy did vary by age. Taken together, this suggests that the mechanisms underlying the effects of attitudes to ageing on health and wellbeing outcomes are likely differ by age group.

The second question that can be asked about relationships between attitudes to aging and health outcomes is whether they differ according to the nature of attitude construct measured. That is, measures of attitudes to aging show considerable diversity in terms of the specific construct(s) they tap into, including experiences or current anxieties about one's own aging, views on aging in general, and expectations about one's own future aging (Faudzi et al. 2019). Gaining a better understanding of how these more specific attitudinal constructs are associated with health and wellbeing outcomes at different ages would therefore help with the development of intervention strategies that target the most relevant construct(s).

The aim of the present study was therefore to examine the moderating effects of age on relationships between attitudes to aging and well-being outcomes in younger adults using measures that capture two different attitudinal constructs: 1) the Reactions to Ageing Questionnaire (RAQ), which primarily assesses respondents' anticipated reactions to being over the age of 65 (Gething, 1994), and 2) The Anxiety about Ageing Scale (AAS), which taps into a 
broader construct that also includes fears and anxieties about current aging and older people (Lasher \& Faulkender, 1993). In line with previous research, we predicted that positive attitudes to aging would be associated with more positive well-being and life satisfaction, after controlling for relevant sociodemographic and health variables (age, gender, education, and self-rated health). In order to examine the extent to which these relationships differ by age, the moderating effect of age on these relationships was examined for each attitude measure.

\section{Method}

\section{Participants}

Participants were an opportunity sample of 911 employees of 68 public agencies (e.g., schools, hospitals, welfare community departments) in Kedah, Malaysia. In order to be eligible to take part in the study, participants had to be aged between $18-60$ years old and be literate in the Malay language. The age of the sample ranged from 18 and 60 years, with a mean age of 36.63 years $(S D=10.03)$. The majority of participants were of Malay ethnicity $(93.4 \%)$, with smaller numbers of participants of Chinese (3.3\%), Indian (2.1\%), and other (1.2\%) ethnicities. The proportion of female participants was higher than male (517 female; 394 male). Approximately $38 \%$ were educated to undergraduate or postgraduate level, with the other $62 \%$ leaving after a high school education or with a certificate/diploma. 


\section{Instruments}

Attitudes to Aging- We used Malay versions of two different measures of attitudes to aging that have been validated for use in people aged under 60: the Reactions to Ageing Questionnaire (RAQ: Gething, 1994), which focuses on participants' anticipated reactions to being over the age of 65; and the Anxiety about Ageing Scale (AAS: Lasher \& Faulkender, 1993), which includes items about fears and anxieties about current aging and older people. The Malay version of the Reactions to Ageing Questionnaire (M-RAQ) is an adapted Malay version of the original RAQ developed by Gething (1994) that was previously validated in the current study sample, and shown to have the expected associations with age and gender Faudzi et al., 2018). It comprises 25 items, each of which is a statement describing positive or negative dimensions related to expectations of what their life will be like when aged over 65 years. Example items include ' $I$ will enjoy having my family around me', 'There is a lot to look forward to in regard to being old', and 'I will be more lonely than I am now'. Participants are requested to specify their agreement with each statement using a five-point scale ranging from 1 (disagree very much) to 5 (agree very much). Scores can range from 25 to 125 , with 18 items reverse-scored such that greater scores indicate more positive attitudes towards aging. This adapted scale has high internal consistency, with a Cronbach's alpha value of 0.88 in the present study.

The Malay version of the Anxiety about Ageing Scale (M-AAS) is an adapted Malay version of the original AAS that was developed by Lasher and Faulkender (1993). It was previously validated in the current study sample, and shown to have an underlying factor structure and relationships with demographic variables that are broadly consistent with previous literature (Faudzi, 2018). This scale emphasizes anxieties or fears about current and future aging, as well as willingness to be together with and help the elderly. Participants are asked to rate the 
extent of their agreement with 19 statements (e.g., I have never dreaded looking old; I have never lied about my age in order to appear younger; I like to go visit my older relatives) on a 5point Likert scale, ranging from strongly agree to strongly disagree to. Seven items are reverse scored, so that higher scores always specify greater levels of anxiety about aging. Scores can range from 19 to 95 . The alpha coefficient for this scale in the current study was .83 , indicating good internal consistency.

Well-being- The Warwick- Edinburgh Mental Well-being Scale (WEMWBS) was developed by Tennant et al. (2007) and consists of 14 items covering both hedonic and eudemonic well-being. Hedonic well-being is associated with the concept of subjective well-being, which is usually interpreted as the balance between negative and positive effect, as well as overall satisfaction with life (Diener, 1984), whilst eudemonic well-being represents aspects of psychological wellbeing (Ryan \& Deci, 2000), such as personal control, self-acceptance and purpose in life (Ryff \& Singer, 2006). This scale has been widely used and validated in more than ten languages, including Asian languages such as Chinese, Japanese and Hindi (Warwick Medical School, 2017). Participants are asked to respond to statements describing their experiences over the past two weeks on 5-point Likert scale, ranging from 1 (none of the time) to 5 (all of the time). Ranging from 14 to 70, higher scores on the WEMWBS represent higher levels of mental wellbeing. The Cronbach's alpha for this scale was 0.90 in the current study, indicating a high level of reliability.

The Satisfaction with Life Scale (SWLS) was developed by Diener, Emmons, Larsen and Griffin in 1985 to assess cognitive judgements of one's life satisfaction. A large body of research has also examined the psychometric properties of the SWLS in many different Asian settings (Lim, 2015; Wu \& Yao, 2006; Ye, 2007). Participants indicate their degree of agreement on five 
items, such as 'The conditions of my life are excellent', and 'In most ways my life is close to my ideal' using a 7-point scale with responses range from 1 (strongly disagree) to 7 (strongly agree). Scores for this scale ranges from 5 to 35 , with higher values indicate greater levels of life satisfaction. In the present study, the Cronbach's alpha score for this scale was .85 .

English versions of the WEMWBS and SWLS were both translated into Malay using a back-translation procedure (Ozolins, 2009). The original and the back-translated English versions were then compared to identify any differences in the meaning of the items, and amended accordingly. As a final check for clarity, the revised translated version of each was then administered to 18 Malay-speaking participants living in the UK using a 'think aloud' procedure (Kaklamanou, Armitage \& Jones, 2013), with minor ambiguities amended until no new issues arose.

Health- The self-report single item asks participants to respond to the phrase, "In general, how would you describe your health?" with one of a five-point scale, where 1 reflects poor and 5 reflects excellent (Ahmad, Jhajj, Stewart, Burghardt \& Bierman, 2014). This instrument has been

found to be predictive of morbidity and mortality (Idler \& Benyami, 1997), indicating its validity as a measure of health. This item was also translated into Malay using the same back-translation and checking procedure as for the WEMWBS and SWLS.

\section{Procedure}

The study used a cross-sectional, correlational design. Data were collected between October and December 2015. Before collecting the data, approval was acquired from the University of 
Manchester Research Ethics Committee and the Malaysian Economic Planning Unit. The researcher then approached organizations (e.g., school, hospitals, community center) listed by the Ministry of Information, Kedah. A letter asking for permission to conduct the study was then sent to the managers of 68 selected agencies. The researcher distributed questionnaire packs to each manager, who was asked to distribute them to their employees. Employees were then asked to complete the questionnaires within the next two weeks, and return them in an opaque envelope into a box that was provided by the researcher. Each questionnaire pack contained a participant information sheet, a brief demographic questionnaire assessing age, gender, and a single-item measure of self-rated health (Idler \& Kasl, 1991), and multiple questionnaires relating to the variables of interest. Additional measures of self-esteem were collected as part of a larger study.

Overall, 1731 questionnaires were distributed to 68 organizations. However, the manager of one organization was unable to distribute the questionnaires because most of their employees were predominantly based outside of the main office. A total of 957 completed questionnaires were returned from the other 67 organizations. Based on the Interagency Language Roundtable Scale (ILR, 2016), five questionnaires were excluded as the participants did not meet the inclusion criterion of Malay language proficiency (for those in level 1 (Elementary Proficiency); 2 (Limited Working Proficiency); and 3 (Professional Working Proficiency); and one further participant had scores that were extreme outliers (more than $3 *$ interquartile ranges from the average). A further 40 participants were excluded due to having high levels (more than 5\%) of overall missing items. Mean substitutions were used to replace missing data in a further 21 cases in which less than $5 \%$ of the data were missing $(2.3 \%$ of total data). The final analyses were 
therefore performed on data from 911 participants. This sample size provided $98 \%$ power to detect small effect sizes in $\mathrm{R}^{2}$ square change values from step 1 to step 2 .

\section{Data Analysis}

Statistical Package for Social Sciences version 23 was used in this study to perform all analyses. Although tolerance and VIF values (at .49 and 2.04, respectively) were not indicative of multicollinearity, scores on the two attitudes measures did show a substantial amount of correlation with one another $(r=-.71)$. For this reason, separate analyses were conducted with each measure. Four hierarchical multiple regression analyses were therefore performed to separately assess the effects of each of the two attitudes to aging measures, with well-being and life satisfaction as dependent variables. The independent variables were entered into blocks; with demographic and health control variables (gender, education and health) added in block 1 as control variables. The total score of M-AAS or M-RAQ, and age, were then added in block 2 as predictors. The interaction of age and the M-AAS or M-RAQ score were then entered into block 3. The variables were centered by subtracting the sample mean from all individual variable scores (Aiken \& West, 1991). Significant age $\times$ M-AAS/M-RAQ interactions were further investigated using the PROCESS function (version 3, model 1) by Hayes (2013) with age as a linear variable.

\section{Results}

\section{Participant Characteristics}

Descriptive data for all measures are provided in Table 1. Mean scores were significantly above the midpoint for the M-RAQ $(M=80.19 / 125, S D=11.15)$ and below the midpoint for the MAAS $(M=49.11 / 95, S D=8.16)$, signifying a tendency towards more positive attitudes. The 
levels of well-being and life satisfaction were also statistically significantly different to the midpoint, indicating generally positive scores (WEMWBS: $M=54.97 / 70, S D=6.68$; SWLS: $M$ $=24.40 / 35, S D=5.36$ ). Moreover, health was rated as being "good" with a mean score of 3.34 $(S D=.69)$, where 3 is considered "good" and 4 is considered "very good" health.

Table 1 about here

\section{Hierarchical Multiple Regression Analysis}

\section{M-AAS and well-being.}

For M-AAS, the first block of demographic variables significantly predicted well-being, explaining $10.7 \%$ of the variance (Table 2). Adding the second block of predictors (age and MAAS score) significantly increased the proportion of the variance explained to $22.8 \%$. When the interaction of age and M-AAS was added in block 3, the variance explained in the model significantly increased to $23.7 \%$. Better health, older age, and M-AAS score were independent predictors of well-being. The interaction between age and M-AAS also significantly predicted well-being $(\mathrm{p} \leq .01)$, indicating that age functioned as moderator of the relationships between anxiety about aging and well-being (Table 2).

Table 2 about here 
Moderation analyses using PROCESS confirmed an interaction between age and M-AAS scores $(b=.008,95 \% C I[.003,0.12], t=3.19, p \leq .001)$. At higher ages the significant negative association between M-AAS and well-being was weaker $(b=-.206,95 \% C I[-.271$, $.140], t=-6.19, p<.001)$ than at younger age $(b=-.354,95 \% C I[-.424,-.284], t=-9.93, p$ $<.001$. This interaction is illustrated in Figure 1a.

Figure 1 about here

\section{M-AAS and life satisfaction.}

The demographic variables (block 1) explained $7.3 \%$ of the variance in life satisfaction (Table 1). The addition of M-AAS score and age in the second block significantly increased the amount of variance explained to $15.0 \%$. Adding the third block (interaction of M-AAS and age) in the model led to a further significant increase to $15.4 \%$ of variance explained. Female gender; better health; older age; and lower AAS score contributed independently to life satisfaction. Further, the interaction term between age and M-AAS also significantly predicted life satisfaction $(p<.05)$, indicating that age functioned as moderator of the relationships between anxiety about aging and life satisfaction (Table 2).

The PROCESS analysis confirmed that age moderated the relationship between M-AAS and life satisfaction, $(b=.004,95 \% C I[.0002, .008], t=2.076, p=.038)$. The direction was the same as for well-being, with a stronger relationship between M-AAS and life satisfaction in younger age $(b=-.197,95 \% C I[-.256,-.139], t=-6.66, \mathrm{p}<.001)$ compared to older age $(b=-$ $.117,95 \% C I[-.171,-.062], t=-4.20, p<.001)$. This is illustrated in Figure $1 \mathrm{~b}$. 


\section{M-RAQ and well-being.}

For the M-RAQ scores, the first block of demographic variables significantly predicted well-being explaining $10.7 \%$ of the variance (Table 3). Adding the second block of predictors (age and M-RAQ score) explained a further $17.7 \%$ of the variance in well-being, but no further increase was found when adding the interaction of age and M-RAQ score in the third block. Better health, older age and higher M-RAQ score were the only variables that predicted a unique contribution to well-being (Table 3). As there was no significant age and M-RAQ score interaction, no moderation analysis using PROCESS was conducted.

\section{M-RAQ and life satisfaction.}

The first block of demographic variables significantly explained $7.3 \%$ of the variance in life satisfaction (Table 3). The addition of predictors (M-RAQ score and age) in the second block significantly increased the amount of variance explained to $12.9 \%$. However, the addition of the third block (interaction of M-RAQ and age) did not significantly increase the variance explained by the model. Female gender, better health, older age and higher RAQ score again each made a unique contribution to predicting life satisfaction (Table 3). There was no significant interaction between age and M-RAQ, thus no moderation analysis was explored.

Table 3 about here 


\section{Discussion}

The aim of this study was to examine whether measures of two different attitudes to aging were associated with wellbeing outcomes in a young population, and the extent to which these relationships were moderated by age. As expected, both measures of attitudes to aging were associated with wellbeing and life satisfaction, with lower scores on the M-AAS, and higher scores on the M-RAQ, associated with increased wellbeing and life satisfaction. These associations remained significant after controlling for sociodemographic variables and selfhealth rated. When measuring anxieties about aging using the M-AAS, both of these associations were moderated by age, such that stronger associations were found in younger age compared to older adults. However, no moderating effects of age were found for these relationships when measuring anticipated reactions to future aging using the M-RAQ.

Overall, the present study found that more positive attitudes to aging (measured by both M-AAS and M-RAQ) in a young sample were associated with well-being and life satisfaction. This is consistent with previous studies showing similar relationships when examining attitudes to aging in older (Bryant et al., 2012; Shenkin et al., 2014, Kalfoss et al., 2010) and younger populations (Joshi et al., 2010; Klusmann et al., 2017; Wurm et al., 2010; Thorpe et al., 2014). They also extend previous findings to show that the relationships between the M-AAS and wellbeing outcomes were moderated by age, with stronger relationships found in younger rather than older participants. However, no such moderating effects were found when using the MRAQ. This difference in the moderating effect of age between measures suggests that the two attitudinal constructs captured by these two measures operate in different ways. In particular, the M-AAS includes items that capture fears and anxieties about both current and future aging, as well as fear of older people (Lasher \& Faulkender, 1993), whereas the M-RAQ specifically asks 
participants to think ahead and imagine how they will feel about their own aging at the age of 65 . These findings suggest that it might specifically be the current emotional/anxiety component of attitudes that differentially affects wellbeing in different age groups.

One explanation for the presence of a moderating effect of age on the M-AAS and wellbeing relationships is that people get better at dealing with anxiety (including age-related anxiety) with increasing age. That is, through experience and maturation, people develop more effective coping strategies (Martin, Rott, Poon, Courtenay \& Lehr, 2001), especially for emotional regulation and problem solving (Gooding, Hurst, Johnson \& Tarrier, 2011), and a more fully-developed repertoire of coping strategies (Aldwin, Sutton, Chiara \& Spiro, 1996). Such effective coping may help to reduce the impact of current anxieties about aging on wellbeing. Interventions focused on coping with aging-related anxieties might therefore be better focused on younger adults, who may be less able to respond effectively to the anxieties they experience.

Some limitations of the current study need to be acknowledged. First, the current data are cross-sectional in nature, which make it impossible to establish directional links between the constructs of interest, or to distinguish the effects of age from cohort effects. Longitudinal studies are therefore necessary in order to better establish the temporal dynamics of these relationships in a single cohort. This would also make it easier to establish, for instance, the extent to which wellbeing is an outcome of, and/or a contributing factor towards, one's attitudes to aging. Second, although our measures of wellbeing, life satisfaction and subjective health had been translated into the Malay language using a robust back-translation and checking procedure, they had not undergone a full-scale validation procedure, and so may not fully or accurately capture the intended constructs. Another limitation of the present study is that includes only 
persons working in the public sector, from a single state within Northern Malaysia, and therefore is not representative of others within this age group, such as students or unemployed persons, or those living in different cultural or geographical areas. Although we did not screen participants on the basis of their physical or mental health, it is also likely that the majority of participants in this study were in relatively good health, as they were able to work. The identified relationships between aging attitudes and well-being and life satisfaction may therefore not be representative of those experiencing significant health problems. Finally, as our sample only included participants aged younger than 60 years of age, we were not able to examine the moderating effects of age in older adult age groups.

These findings have some important clinical and practical implications. First, our study found that relationships specifically focusing on the current emotional/anxiety component of attitudes to aging are stronger in younger compared to older participants. As such, interventions aiming at the promotion of wellbeing through coping with aging-related anxieties might be better focused on younger adults, who may be less able to respond effectively to the anxieties they experience. Second, the different patterns of results seen for the two measures of attitudes to aging highlight the need for greater attention to, and clarity about, the conceptual similarities and differences between alternative attitudes to aging constructs. Future research aimed at understanding the mechanisms underlying relationships between attitudes to ageing and health/behavioral outcomes should therefore use measures that enable different attitudinal constructs to be isolated, so that the differential effects of each component can be examined. 


\section{Acknowledgements}

The research was supported by the NIHR Manchester Biomedical Research Centre and the NIHR Greater Manchester Patient Safety Translational Research Centre, and a PhD studentship from the Malaysian Ministry of Education awarded to FNMF. 


\section{References}

Ahmad, F., Jhajj, A.K., Stewart, D.E., Burghardt, M., \& Bierman, A.S. (2014). Single item measures of self-rated mental health: a scoping review, BMC Health Services Research, 14, 1-11. doi: 10.1186/1472-6963-14-398.

Aiken, L.S., \& West, S.G. (1991). Multiple regressions. Testing and interpreting interaction. London: Sage Publications.

Aldwin,C.M., Sutton, K.J., Chiara, G., \& Spiro, A. III. (1996). Age differences in stress, coping, and appraisal: Findings from the normative aging study. Journal of Gerontology (B): Psychological Sciences,4, 179-188. doi:10.1093/geronb/51B.4.P179

Bryant, C. Bei, B., Gilson, K., Komiti, A., Jackson, H., \& Judd, F. (2012). The relationship between attitudes to aging and physical and mental health in older adults. International Psychogeriatrics. 24, 1674-1683. doi:10.1017/S1041610212000774

Burns, D.J., \& Brady, J. (1992). A cross-cultural comparison of the need for uniqueness in Malaysia and the United States. The Journal of Social Psychology, 132, 487-495. doi: $10.1080 / 00224545.1992 .9924728$

Diener, E. (1984). Subjective well-being. Psychological Bulletin, 95, 542-575.doi:10.1037//0033 2909.95.3.542

Diener, E., Emmons, R. A., Larsen, R. J., \& Griffin, S. (1985). The satisfaction with life scale. Journal of Personality Assessment, 49, 71-75. doi:10.1207/s15327752jpa4901_13

Faudzi, F.N.B.M. (2018). A psychometric evaluation of attitudes to ageing measures among younger people. Unpublished $\mathrm{PhD}$ thesis, University of Manchester.

Faudzi, F.N.M., Armitage, C.J., Bryant, C.A., \& Brown, L. J.E. (2018). Cultural adaptation to the measurement of attitudes to ageing: Psychometric assessment of the Malay Reactions to 
Ageing Questionnaire. Assessment. Advance online publication available April $12^{\text {th }}, 2018$. doi: $10.1177 / 1073191118766400$

Faudzi, F.N.M., Armitage, C.J., Bryant, C.A., \& Brown, L. J.E. (2019). A systematic review of the psychometric properties of self-report measures of attitudes to ageing. Research on Aging, manuscript in press.

Gething, L. (1994). Health professional attitudes towards ageing and older people: preliminary report of the Reactions to Ageing Questionnaire. Australasian Journal on Ageing, 13, 7781. doi:10.1111/j.1741-6612.1994.tb00646.x/full

Gilbert, C.N., \& Ricketts, K.G. (2008). Children's attitudes toward older adults and aging:। synthesis of research. Educational Gerontology, 34, 570-586.doi:10.1080/03601270801900420

Gooding, P.A., Hurst, A., Johnson, J., \& Tarrier, N. (2011). Psychological resilience in young and older adults. International Journal of Geriatrics Psychiatry, 27, 262-270. doi.org/10.1002/gps.2712

Hayes, A.F. (2013). Introduction to mediation, moderation, and conditional Process analysis.A regression-based approach. New York: The Guilford Press.

Hess, T.M. (2006). Attitudes toward aging and their effects on behavior. In: Birren, J.E., Schaie, K.W. (Eds). Handbook of the psychology of aging (pp. 379-406). San Diego: CA: Academic Press.

Idler E, \& Benyami Y. (1997). Self-rated health and mortality: a review of 27 community studies. Journal Health Social Behaviour, 38, 21-37. doi: 10.2307/2955359. 60

Idler, E.L. \& Kasl, S. (1991). Health perceptions and survival: Do global evaluations of health status really predict mortality? Journal of Gerontology, 46, 55 - 65. doi:10.1093/geronj/46.2.S55 
Interagency Language Roundtable. (ILR) (2016) Retrieved from gov.tilr.org.

Ismail, N., Tan, J-P., \& Ibrahim, R. (2009). The relationship between parental belief on filial-piety and child psychosocial adjustment among Malay families. Pertanika Journal Social Sciences, 17, 215-224.

Joshi, V. D., Malhotra, R., Lim, J.F.Y., Ostbye, T., \& Wong, M. (2010). Validity and reliability of the expectations regarding aging (ERA-12) instrument among middle-aged Singaporeans. Annals of the Academy of Medicine Singapore, 39, 394-398

Kaklamanou, D., Armitage, C.J., \& Jones, C.R. (2013). A further look into compensatory health beliefs: A think aloud study. British Journal of Health Psychology, 18, 139-154. doi:10.1111/j.2044-8287.2012.02097.x

Kalfoss, M.H., Low, G., Molzahn, A.E. (2010). Reliability and validity of the attitudes to ageing questionnaire for Canadian and Norwegian older adults. Scandinavian Journal of Caring Sciences, 24, 75-85. doi:10.1111/j.1471-6712.2010.00786.x

Klusmann, V., Sproesser, G., Wolff, J.K. \& Renner, B. (2017). Positive self-perception of aging promotes healthy eating behavior across the life span via social-cognitive processes. Journal of Gerontology (B): Psychological Sciences, Advance online publication: doi:10.1093/geronb/gbx139

Kooshiar. H., Yahaya, N., Hamid, T.A., Abu Samah, A., \& Sedaghat, J.V. (2012) Living arrangementand life satisfaction in older Malaysians: The mediating role of social support function. PLoS ONE 7, 1-6. doi:10.1371/journal.pone.0043125

Kornadt, A. E., \& Rothermund, K. (2015). Views on aging: Domain-specific approaches and implications for developmental regulation. Annual Review of Gerontology and Geriatrics, 35, 121-144. doi:10.1891/0198-8794.35.121 
Kornadt, A.E., Voss, P., \& Rothermund, K. (2015). Hope for the best, prepare for the worst Future self-views and preparation for age-related changes. Psychology and Aging, 30, 967976. doi:10.1037/pag0000048

Lasher, K., P., \& Faulkender. P.J. (1993). Measurement of aging anxiety: development of the anxiety about aging scale. International Journal of Aging and Human Development 37,247-59.

Levy, B.R. (2009). Stereotype embodiment. A psychosocial approach to aging. Current Directions in Psychological Science, 18, 332 - 336. doi:10.1111/j.1467 8721.2009.01662.x

Lockenhoff, C.E., Lee, D.S., Buckner, K.M.L., Moreira, R.O., Mertinez, S.J. \& Sun, M.Q. (2015). Cross-cultural differences in attitudes about aging: Moving beyond the East-West dichotomy. In.Sheung- Tak, C., Iris, C., Fung, H.H., Lydia, W.L. Jean, W. Successful aging: Asian perspectives (pp. 321-333). Springer Dordrencht, Heildelberg: New York.

Lim, Y-J. (2015). Psychometric characteristics of the Korean version of the Satisfaction with Life Scale adapted for children. Canadian Journal of School Psychology, 30, 246 - 251. doi:10.1177/0829573515590012

Martin, P., Rott, C., Poon L.W., Courtenay, B., \& Lehr, U. (2001). A molecular view of coping behavior in older adults. Journal of Aging and Health, 13, 72 - 91. doi:10.1177/089826430101300104

O’Hanlon, A., \& Coleman, P. (2008). Attitudes towards aging: Adaptation, development and growth into later years. In. J.F. Nussbaum \& J. Coupland (2nd Eds.). Handbook of communication and aging research (pp. 31-67). New York, NY: Routledge.

Ozolins, U. (2009). Back translation as a means of giving translators a voice. The International Journal for Interpreting and Translation Research, 1, 1-13. 
Ryan, R. M., \& Deci, E. L. (2000). Self-determination theory and the facilitation of intrinsic motivation, social development, and well-being. American Psychologist, 55, 68-78. doi:10.1037/0003-066X.55.1.68

Ryff, C.D. \& Singer, B.H. (2006). Know thyself and become what you are: A eudaimonic approach to psychological well-being. Journal of Happiness Studies, 9, 13-39. doi:10.1007/s10902 006 9019-0

Shenkin, S. D., Laidlaw, K., Allerhand, M., Mead, G. E., Starr, J.M. and Deary, I. J. (2014). Life course influences of physical and cognitive function and personality on attitudes to aging in the Lothian birth cohort 1936. International Psychogeriatrics, 26, 1-14. doi: 10.1017/S1041610214000301.

Teh, J.K., Ng, S.T., Tey, N.P., \& Siti Norlasiah, I. (2013). Ethnicity and support for parent in Malaysia. Asian Women, 29, 51-72.

Tennant, R., Hiller, L., Fishwick, R., Platt, S., Joseph, S., Weich, S., Parkinson, J., Secker, J., \& Stewart-Brown, S. (2007). The Warwick-Edinburgh Mental Well-Being Scale (WEMWBS): Development and UK validation. Health and Quality of Life Outcome, 5, 113. doi: 101186/1477-7252-5-63.

Thorpe, A.M., Pearson, J.F., Schluter, P.J., Spittlehouse, J.K., \& Joyce, P.R. (2014). Attitudes to aging in midlife are related to health conditions and mood. International Psychogeriatrics, 26, 2061 2071. doi: 10.1017/S1041610214001550

Warwick Medical School (2017). The Warwick-Edinburgh Well-being Scale (WEWMBS). Retrieved from http://www2.warwick.ac.uk/fac/med/research/platform/wemwbs/ Wu, C-H., \& Yao, G. (2006). Analysis of factorial invariance across gender in the Taiwan version of the Satisfaction with Life Scale. Personality and Individual Differences, 40, 
1259-1268. doi: 10.1016/j.paid.2005.11.012

Wurm, S., Diehl, M., Kornadt, A.E., Westerhof G.J., \& Wahl, H.-W. (2017). How do views on aging affect health outcomes in adulthood and late life? Explanations for an established connection. Developmental Review, 46, 27-43. Doi: 10.1016/j.dr.2017.08.002

Wurm, S., Tomasik, M.J., \& Tesch-Romer, C. (2010). On the importance of a positive view on ageing for physical exercise among middle-aged and older adults: Cross-sectional and longitudinal findings. Psychology \& Health, 25, 25-42. doi: 10.1080/08870440802311314

Ye, S. (2007). Validation of the temporal satisfaction with life scale in a sample of Chinese university students. Social Indicators Research, 80, 617-628. doi: 10.1007/s11205-006 $0010-2$ 
Table 1: Descriptive data for key variables.

\begin{tabular}{lll}
\hline $\begin{array}{l}\text { Variable (and } \\
\text { possible range) }\end{array}$ & Mean score (SD) & Range \\
\hline M-AAS (19-95) & $49.11(8.16)$ & $21-75$ \\
M-RAQ (25-125 & $80.19(11.15)$ & $42-117$ \\
WEMWBS (14-70) & $54.97(6.68)$ & $32-70$ \\
SWLS (5-35) & $24.40(5.36)$ & $8-35$ \\
Health (1-5) & $3.34(0.69)$ & $1-5$ \\
\hline
\end{tabular}

Health (1-5) 
Table 2: Hierarchical Multiple Regressions Analyses of Relationships between M-AAS and Well-Being and Life Satisfaction Outcomes

\begin{tabular}{|c|c|c|c|c|c|c|c|c|c|}
\hline & \multirow[b]{2}{*}{ Predictor } & \multicolumn{4}{|c|}{ Well-being } & \multicolumn{4}{|c|}{ Life Satisfaction } \\
\hline & & $\Delta \mathrm{R}^{2}$ & $\mathbf{B}$ & SE & $\boldsymbol{\beta}$ & $\Delta \mathrm{R}^{2}$ & B & SE & $\boldsymbol{\beta}$ \\
\hline Step 1 & & $.107 * *$ & & & & $.073 * *$ & & & \\
\hline & Gender $^{\mathrm{a}}$ & & -.493 & .424 & -.037 & & .429 & .347 & .040 \\
\hline & Education $^{\mathrm{b}}$ & & .770 & .435 & .056 & & .672 & .356 & .061 \\
\hline & Health & & 3.131 & .315 & $.313 * *$ & & 2.066 & .258 & $.257 * *$ \\
\hline Step 2 & & $.121 * *$ & & & & $.077 * *$ & & & \\
\hline & Gender $^{\mathrm{a}}$ & & .096 & .401 & .007 & & .886 & .338 & $.082 *$ \\
\hline & Education $^{\mathrm{b}}$ & & .551 & .406 & .040 & & .512 & .342 & .046 \\
\hline & Health & & 2.611 & .98 & $.261 * *$ & & 1.788 & .251 & $.223 * *$ \\
\hline & Age & & .043 & .020 & $.065^{*}$ & & .063 & .017 & $.116^{* *}$ \\
\hline & M-AAS & & -.274 & .025 & $-.336 * *$ & & -.154 & .021 & $-.235 * *$ \\
\hline Step 3 & & $.009 * *$ & & & & $.004 *$ & & & \\
\hline & Gender $^{\mathrm{a}}$ & & .140 & .399 & .010 & & .910 & .338 & $.084 *$ \\
\hline & Education $^{\mathrm{b}}$ & & .623 & .404 & .045 & & .552 & .342 & .050 \\
\hline & Health & & 2.689 & .297 & $.269 * *$ & & 1.830 & .251 & $.228 * *$ \\
\hline & Age & & .049 & .020 & $.073 *$ & & .065 & .017 & $.122 * *$ \\
\hline & M-AAS & & -.280 & .025 & $-.342 * *$ & & -.157 & .021 & $-.239 * *$ \\
\hline & Age $\times$ M-AAS & & .007 & .002 & $.095 * *$ & & .004 & .002 & $.064 *$ \\
\hline $\begin{array}{l}\text { Total } \\
\mathrm{R}^{2}\end{array}$ & & $.237 * *$ & & & & $.154^{*}$ & & & \\
\hline
\end{tabular}


Table 3: Hierarchical Multiple Regressions Analyses of Relationships between M-RAQ and Well-Being and Life Satisfaction Outcomes

\begin{tabular}{|c|c|c|c|c|c|c|c|c|c|}
\hline & \multirow[b]{2}{*}{ Predictor } & \multicolumn{4}{|c|}{ Well-being } & \multicolumn{4}{|c|}{ Life Satisfaction } \\
\hline & & $\Delta \mathrm{R}^{2}$ & $\mathbf{B}$ & SE & $\boldsymbol{\beta}$ & $\Delta \mathrm{R}^{2}$ & B & SE & $\boldsymbol{\beta}$ \\
\hline Step 1 & & $.107 * *$ & & & & $.073 * *$ & & & \\
\hline & Gender $^{\mathrm{a}}$ & & -.493 & .424 & -.037 & & .429 & .347 & .040 \\
\hline & Education $^{\mathrm{b}}$ & & .770 & .435 & .056 & & .672 & .356 & .061 \\
\hline & Health & & 3.131 & .315 & $.313 * *$ & & 2.066 & .258 & $.257 * *$ \\
\hline Step 2 & & $.071 * *$ & & & & $.056 * *$ & & & \\
\hline & Gender $^{\mathrm{a}}$ & & -.006 & .414 & .000 & & .837 & .342 & $.077 *$ \\
\hline & Education $^{\mathrm{b}}$ & & .705 & .418 & .051 & & .600 & .346 & .054 \\
\hline & Health & & 2.710 & .309 & $.271 * *$ & & 1.824 & .255 & $.227 * *$ \\
\hline & Age & & .066 & .021 & $.098 *$ & & .074 & .017 & $.138 * *$ \\
\hline & M-RAQ & & 1.43 & .019 & $.238 * *$ & & .086 & .015 & $.179 * *$ \\
\hline Step 3 & & .003 & & & & .002 & & & \\
\hline & Gender $^{\mathrm{a}}$ & & -.039 & .414 & -.003 & & .814 & .342 & $.075^{*}$ \\
\hline & Education $^{\mathrm{b}}$ & & .753 & .419 & .055 & & .622 & .346 & .057 \\
\hline & Health & & 2.717 & .308 & $.272 * *$ & & 1.829 & .255 & $.228 * *$ \\
\hline & Age & & .068 & .021 & $.102 * *$ & & .076 & .017 & $.141 * *$ \\
\hline & M-RAQ & & .143 & .019 & $.019 * *$ & & .087 & .015 & $.180 * *$ \\
\hline & $\begin{array}{l}\text { Age } \times \text { M- } \\
\text { RAQ }\end{array}$ & & -.003 & .002 & .002 & & -.002 & .001 & -.045 \\
\hline $\begin{array}{l}\text { Total } \\
\mathrm{R}^{2}\end{array}$ & & .180 & & & & .131 & & & \\
\hline
\end{tabular}



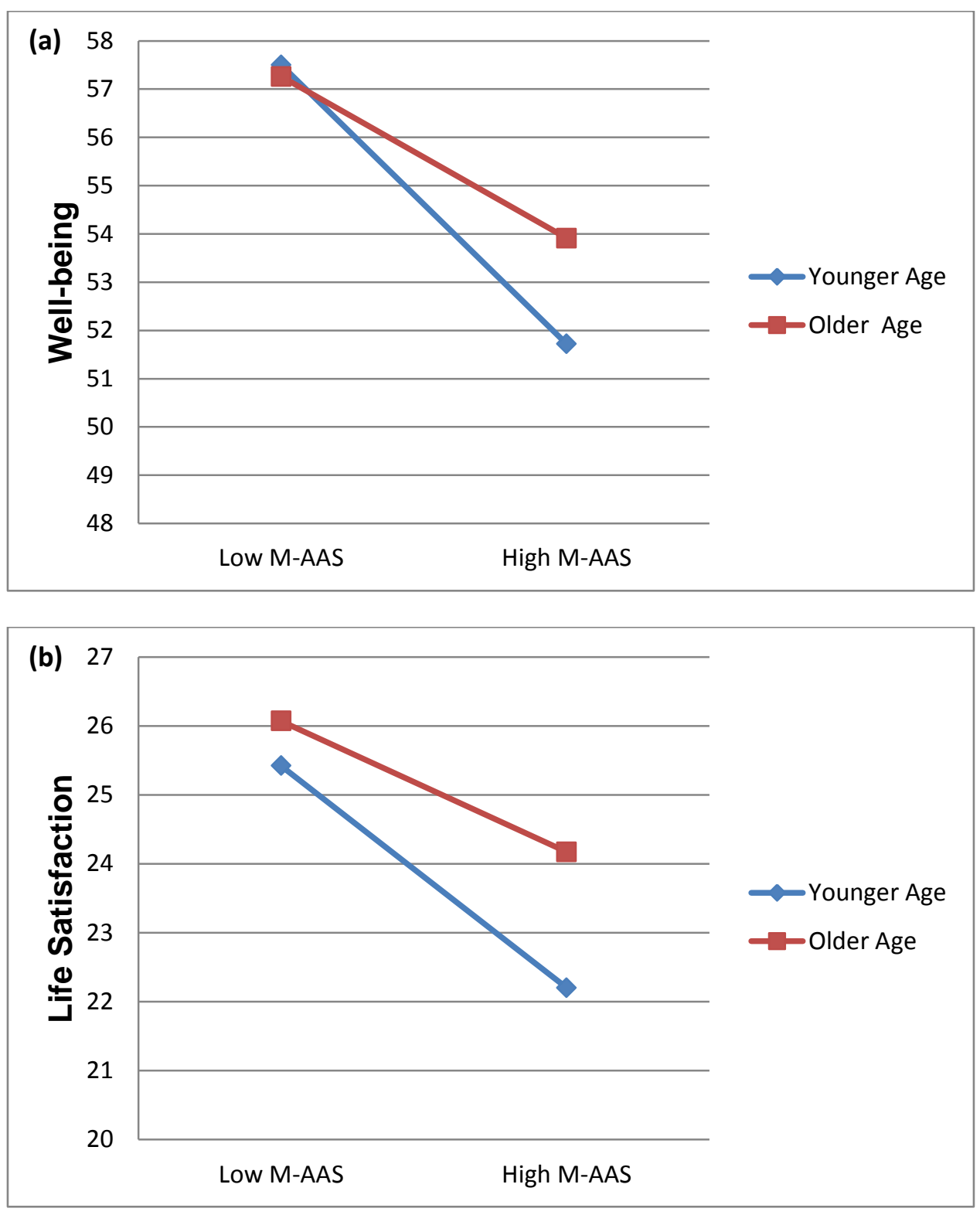

Figure 1: Moderating Effects of Age on the Relations between M-AAS scores and Well-being (a) and Life Satisfaction (b). 